\title{
REGRESI ROBUST MM-ESTIMATOR UNTUK MEMODELKAN JUMLAH KEMATIAN BALITA DI PROVINSI JAWA TIMUR TAHUN 2017
}

\author{
ATIKAH RAHMAH PUTRI, HAZMIRA YOZZA, FERRA YANUAR \\ Program Studi S1 Matematika, \\ Fakultas Matematika dan Ilmu Pengetahuan Alam, Universitas Andalas, \\ Kampus UNAND Limau Manis Padang, Indonesia. \\ email : atikahrahmahputri@gmail.com, hazmirayozza@sci.unand.ac.id, \\ ferrayanuar@sci.unand.ac.id
}

Diterima 15 Desember 2020 Direvisi 29 Desember 2020 Dipublikasikan 12 Januari 2021

\begin{abstract}
Abstrak. Dengan berakhirnya MDGs, PBB kembali membuat agenda pembangunan yaitu SDGs dengan salah satu targetnya yaitu mengakhiri kematian balita yang dapat dicegah, dengan seluruh negara menurunkan Angka Kematian Balita 25 per 1000 kelahiran hidup. Provinsi Jawa Timur merupakan salah satu provinsi yang memiliki angka kematian absolut yang masih tinggi yaitu sebanyak 4.464 balita meninggal pertahun. Untuk menganalisis faktor yang mempengaruhi jumlah kematian balita digunakan analisis regresi robust MM-estimator. MM-Estimator merupakan gabungan dari S-Estimator dan M-Estimator sehingga metode ini mempunyai efisiensi yang tinggi dan nilai resisten yang tinggi pula, sehingga metode MM-Estimator merupakan metode yang terbaik dibandingkan metode regresi robust lainnya. Hasil analisis menunjukkan bahwa variabel bebas yang mempe- ngaruhi jumlah kematian balita di Provinsi Jawa Timur adalah jumlah kasus pneumonia pada balita.
\end{abstract}

Kata Kunci: Regresi Robust MM-Estimator, Jumlah Kematian Balita, Outlier

\section{Pendahuluan}

Pada tahun 2000, kepala negara beserta perwakilan 189 negara anggota Perserikatan Bangsa-Bangsa (PBB) menyepakati Deklarasi Millenium atau Millennium Development Goals (MDGs). Deklarasi tersebut memiliki delapan target, salah satunya adalah menurunkan $2 / 3$ jumlah kematian anak yang berusia dibawah lima tahun (balita) pada tahun 2015. Berakhirnya Millenium Development Goals (MDGs), PBB kembali membuat agenda pembangunan yaitu Sustainable Development Goals (SDGs) yang merupakan lanjutan dari MDGs dengan salah satu targetnya yaitu pada tahun 2030, mengakhiri kematian bayi dan anak di bawah lima tahun yang dapat dicegah, dengan seluruh negara menurunkan Angka Kematian Neonatal seti-

*penulis korespondensi 
daknya hingga 12 per 1000 kelahiran hidup dan Angka Kematian Balita 25 per 1000 kelahiran hidup. [10]

Provinsi Jawa Timur merupakan salah satu provinsi yang memiliki angka kematian absolut yang masih tinggi yaitu sebanyak 4.464 balita meninggal pertahun [5]. Salah satu cara untuk menurunkan angka kematian absolut balita tersebut adalah dengan mengetahui segala masalah yang terkait dengan faktor yang diperkirakan mempengaruhi angka kematian absolut balita tersebut. Oleh karena itu, perlu dianalisis faktor yang mempengaruhi jumlah kematian balita agar masyarakat dan pemerintah dapat memiliki upaya untuk menurunkan jumlah kematian balita. Salah satu analisis yang dapat dilakukan untuk menganalisis faktor yang mempengaruhi jumlah kematian balita adalah dengan regresi robust. Regresi robust merupakan estimasi yang lebih efisien dalam menangani outlier pada data tanpa harus membuang outlier tersebut dalam analisis.

\section{Landasan Teori}

\subsection{Outlier dan Pengamatan Berpengaruh}

Outlier adalah data yang tidak mengikuti pola umum pada model regresi yang dihasilkan [9]. Adanya outlier dapat disebabkan oleh kesalahan ketika memasukkan data, kegagalan menspesifikasi adanya data hilang dalam program komputer, adanya data yang bukan berasal dari populasi yang diambil sebagai sampel, dan variabel dalam populasi memiliki nilai ekstrim serta tidak berdistribusi normal. Akibat dari adanya outlier diantaranya variansi pada data menjadi lebih besar, interval dan range pada data menjadi lebar, dan mean tidak dapat menunjukkan nilai yang sebenarnya. [4]

Salah satu cara untuk mendeteksi outlier adalah dengan $R$-student. Perhitungan R-student pada pengamatan ke- $i$ dapat dinyatakan secara umum sebagai [8]

$$
t_{i}=\frac{e_{i}}{s_{(i)}\left(1-h_{i i}\right)^{1 / 2}}
$$

Jika terdapat outlier pada data, analisis dapat dilakukan dengan mengeluarkan outlier yang telah teridentifikasi kemudian tetap menggunakan metode kuadrat terkecil dalam menduga koefisien regresi [9]. Namun akan lebih bijaksana untuk tidak mengabaikan outlier begitu saja. Adakalanya outlier dapat memberikan informasi yang tidak bisa diberikan oleh titik data lainnya. Outlier seperti ini biasanya dikategorikan sebagai pengamatan berpengaruh [8].

Pengamatan yang berpengaruh adalah pengamatan yang baik secara individu atau bersama-sama dengan beberapa pengamatan lainnya, memiliki pengaruh yang jauh lebih besar terhadap berbagai nilai estimasi (koefisien, standar error, nilai-t, dsb) dibandingkan pengaruh sebagian besar pengamatan lainnya [1]. Pengamatan berpengaruh memiliki dampak pada model koefisien regresi yang dihasilkan karena dalam beberapa kasus, estimasi parameter lebih bergantung pada pengamatan berpengaruh daripada mayoritas data. Oleh karena itu, perlu dilakukan deteksi pengamatan berpengaruh dan menilai dampaknya terhadap model.

Beberapa metode pendeteksian pengamatan berpengaruh antara lain [8]: 
(1) Cooks Distance digunakan untuk mengidentifikasi apakah suatu pengamatan berpengaruh terhadap semua estimasi koefisien regresi. Perhitungan Cook's Distance dapat dinyatakan secara umum dengan

$$
D_{i}=\frac{\left(\hat{\boldsymbol{\beta}}_{(i)}-\hat{\boldsymbol{\beta}}\right)^{\prime} \mathbf{M}\left(\boldsymbol{\beta}_{(i)}-\hat{\boldsymbol{\beta}}\right)}{c}, i=1,2, \cdots, n
$$

Suatu data pengamatan dikatakan pengamatan berpengaruh terhadap koefisien regresi jika nilai $D_{i}>4 / n$.

(2) DFFITS digunakan untuk mengetahui apakah suatu pengamatan ke- $i$ berpengaruh terhadap model regresi yang ditinjau dari nilai dugaan $y$-nya. Perhitungan DFFITS dapat dinyatakan secara umum sebagai

$$
\operatorname{DFFITS}_{i}=t_{i} \sqrt{\frac{h_{i i}}{1-h_{i i}}}
$$

Suatu pengamatan ke- $i$ dikatakan berpengaruh terhadap nilai fitnya apabila pengamatan tersebut memiliki nilai $\left|D F F I T S_{i}\right|>2 \sqrt{\frac{p}{n}}$.

(3) DFBETAS digunakan untuk menyatakan pengaruh suatu pengamatan ke- $i$ terhadap koefisien ke- $j$. DFBETAS dapat dihitung dari

$$
\operatorname{DFBETAS} S_{j, i}=\frac{\hat{\beta}_{j} \hat{\beta}_{j(i)}}{\sqrt{s_{(i)}^{2} C_{j j}}}
$$

Suatu pengamatan ke- $i$ dikatakan berpengaruh terhadap koefisien ke- $j$ apabila pengamatan tersebut memiliki nilai $\left|D F B E T A S_{j, i}\right|>\frac{2}{\sqrt{n}}$.

(4) COVRATIO adalah suatu ukuran yang menggambarkan pengaruh pengamatan ke- $i$ terhadap ketelitian estimasinya. Nilai COVRATIO dihitung dari

$$
\operatorname{COVRATIO} i=\frac{\left(s_{(i)}^{2}\right)^{p}}{\left(M S_{R e s}\right)^{p}} \frac{1}{1-h_{i i}}
$$

Pengamatan ke- $i$ dikatakan sebagai pengamatan berpengaruh terhadap ketelitian estimasinya jika nilai $\operatorname{COVRATIO}{ }_{i}>1+\frac{3 p}{n}$ atau $C O V \operatorname{RATIO}{ }_{i}<$ $1-\frac{3 p}{n}$.

\subsection{Regresi Robust}

Regresi robust diperkenalkan oleh Andrews pada tahun 1972 dan merupakan solusi alternatif untuk mengestimasi parameter regresi ketika terdapat outlier yang mempengaruhi model regresi. Metode ini penting untuk menganalisa data yang dipengaruhi oleh outlier dengan hasil model yang resisten terhadap outlier. Resisten artinya tidak dipengaruhi oleh perubahan besar pada sebagian kecil data atau perubahan sedikit pada sebagian besar data. [7]

Perbedaan antara metode kuadrat terkecil dengan regresi robust yaitu pada metode kuadrat terkecil data diberi bobot yang sama dalam mengestimasi parameter sedangkan pada regresi robust data diberi bobot yang berbeda dimana bobot yang lebih kecil diberikan pada data yang terdeteksi sebagai outlier. Karena bobot yang diberikan berbeda maka pada pendugaan digunakan metode kuadrat terkecil 
terboboti ( Weighted Least Square). Dalam pengaplikasikannya, pendugaan parameter dilakukan dalam beberapa iterasi sehingga dengan kata lain. pendugaan parameter model dilakukan menggunakan IRLS (Iteratively Reweighted Least Square).

Beberapa metode robust yang dapat digunakan dalam analisis regresi adalah sebagai berikut.

\subsubsection{Robust M-Estimator}

Salah satu cara mengestimasi koefisien parameter pada regresi robust adalah MEstimator. M-Estimator diperkenalkan oleh Huber pada tahun 1973. Pada umumnya regresi robust M-Estimator merupakan estimasi yang meminimumkan fungsi $\rho$ (fungsi objektif) yang dapat ditulis sebagai berikut[8]

$$
\hat{\beta}=\arg \min _{\beta} \sum_{i=1}^{n} \rho\left(u_{i}\right)=\arg \min _{\beta} \sum_{i=1}^{n} \rho\left(\frac{y_{i}-\sum_{j=0}^{k} x_{i j} \beta_{j}}{s}\right)
$$

dengan $u_{i}=\frac{e_{i}}{s}$ dan $s$ adalah skala estimasi robust dengan formula sebagai berikut

$$
s=\frac{M A D}{0.6745}=\frac{\text { median }\left|e_{i}-\operatorname{median}\left(e_{i}\right)\right|}{0.6745}
$$

untuk fungsi $\rho$ digunakan fungsi objektif Tuckey Bisquare dengan $c=4.685$ yang dinyatakan sebagai

$$
\rho\left(u_{i}\right)=\left\{\begin{array}{lc}
\frac{c^{2}}{6}\left[1-\left[1-\left(\frac{u_{i}}{c}\right)^{2}\right]^{2}\right], & \left|u_{i}\right| \leqslant c \\
\frac{c^{2}}{6}, & \left|u_{i}\right|>c
\end{array}\right.
$$

Fungsi pembobot Tuckey Bisquare dinyatakan sebagai berikut

$$
w_{i}=w\left(u_{i}\right)=\frac{\psi\left(u_{i}\right)}{u_{i}}=\left\{\begin{array}{l}
{\left[1-\left(\frac{u_{i}}{c}\right)^{2}\right]^{2},} \\
0, \quad\left|u_{i}\right|>c
\end{array}\right.
$$

Untuk meminimumkan fungsi $\rho$ pada Persamaan (2.6) digunakan turunan parsial pertama fungsi objektif $\rho$ terhadap $\beta_{j}$ dimana $j=0,1, \cdots, k$ yang selanjutnya disamakan dengan 0 , sehingga diperoleh $[6]$

$$
\sum_{i=1}^{n} x_{i j} \psi\left(\frac{y_{i}-\sum_{j=0}^{k} x_{i j} \beta_{j}}{s}\right)=0
$$

dengan $\psi\left(u_{i}\right)=\rho^{\prime}\left(u_{i}\right)$ dan $x_{i j}$ adalah pengamatan ke- $i$ pada variabel bebas ke- $j$ dan $x_{i 0}=1$.

Persamaan (2.9) dapat ditulis dalam notasi matriks sebagai berikut

$$
\mathbf{X}^{\prime} \mathbf{W X} \hat{\boldsymbol{\beta}}=\mathbf{X}^{\prime} \mathbf{W} \mathbf{Y}
$$

Persamaan (2.10) diselesaikan secara iteratif dengan Iteratively Reweight Least Square yang dinyatakan sebagai berikut

$$
\hat{\boldsymbol{\beta}}^{(\boldsymbol{q}+\mathbf{1})}=\left(\mathbf{X}^{\prime} \mathbf{W}^{(q)} \mathbf{X}\right)^{-1}\left(\mathbf{X}^{\prime} \mathbf{W}^{(q)} \mathbf{Y}\right) .
$$

Proses iterasi dihentikan jika $\hat{\beta}$ konvergen, dengan kata lain jika $\left|\hat{\beta}_{j}^{(q+1)}-\hat{\beta}_{j}^{(q)}\right|$ cukup kecil atau sama dengan 0 , untuk $j=0,1, \cdots, k$. [3] 


\subsubsection{Robust S-Estimator}

S-Estimator merupakan metode yang diperkenalkan oleh Rousseeuw dan Yohai pada tahun 1984. S-estimator didasarkan pada skala residual M-estimator. Sestimator dapat didefinisikan sebagai [9]:

$$
\hat{\beta}_{s}=\min _{\hat{\beta}} s\left(e_{1}, \cdots, e_{n}\right),
$$

yang artinya $\hat{\beta}$ diperoleh dengan menentukan estimator skala robust $s$ yang minimum dengan $e_{i}(i=1,2, \cdots, n)$ merupakan residual ke- $i$ dimana:

$$
s=\sqrt{\frac{1}{n K} \sum_{i=1}^{n} w_{i} e_{i}^{2}},
$$

dengan $K=0.1995, w_{i}$ adalah fungsi pembobot Tuckey Biquare dan estimasi $s$ awal sebagai berikut

$$
s=\frac{M A D}{0.6745}=\frac{\text { median } \mid e_{i}-\text { median }\left(e_{i}\right) \mid}{0.6745} .
$$

\subsubsection{Robust MM-Estimator}

MM-estimator adalah metode yang pertama kali diperkenalkan oleh Yohai pada tahun 1987. MM-estimator merupakan langkah untuk mengestimasi parameter regresi menggunakan S-estimator yang meminimumkan scale dari galat pada Mestimator kemudian dilanjutkan dengan M-estimator. MM-estimator adalah solusi dari[2]:

$$
\hat{\beta}=\arg \min _{\beta} \sum_{i=1}^{n} \rho\left(u_{i}\right)=\arg \min _{\beta} \sum_{i=1}^{n} \rho\left(\frac{y_{i}-\sum_{j=0}^{k} x_{i j} \beta_{j}}{s}\right),
$$

dimana $x_{i j}$ adalah pengamatan ke- $i$ pada variabel bebas ke- $j, s$ adalah standar deviasi yang diperoleh dari galat dari S-estimator dan $\rho$ adalah fungsi objektif Tuckey Bisquare.

\section{Metode Penelitian}

Data yang digunakan dalam penelitian ini adalah data jumlah kematian balita di kabupaten/kota Provinsi Jawa Timur tahun 2017. Data pada penelitian ini didapatkan dari Profil Kesehatan Provinsi Jawa Timur tahun 2017.

Variabel tak bebas dalam penelitian ini adalah jumlah kematian balita di 38 kabupaten/kota di Provinsi Jawa Timur tahun 2017. Variabel bebas yang digunakan dalam penelitian ini adalah jumlah kasus pneumonia pada balita $\left(X_{1}\right)$, persentase penanganan komplikasi kebidanan $\left(X_{2}\right)$, persentase berat bayi lahir rendah (BBLR) $\left(X_{3}\right)$, persentase balita balita mendapat vitamin $\mathrm{A}\left(X_{4}\right)$, jumlah kasus gizi buruk pada balita $\left(X_{5}\right)$, persentase pemberian imunisasi BCG $\left(X_{6}\right)$, dan persentase pemberian imunisasi $\mathrm{Hb}\left(X_{7}\right)$.

Tahap-tahap yang dilakukan adalah:

(1) Mendeskripsikan data yang akan digunakan dalam penelitian. 
(2) Analisis data dengan Metode Kuadrat Terkecil.

(3) Melakukan pendeteksian outlier dengan R-student.

(4) Melakukan pendeteksian Pengamatan berpengaruh dengan Cook's Distance, DFFITS, DFBETAS, dan COVRATIO.

(5) Membentuk model regresi Robust MM-Estimator.

(6) Menganalisis faktor yang mempengaruhi jumlah kematian balita.

\section{Pembahasan}

\subsection{Pendeteksian Outlier dan Pengamatan Berpengaruh}

Dengan menggunakan metode kuadrat terkecil biasa, diperoleh persamaan regresi:

$$
\begin{aligned}
\widehat{y}= & 24.933+0.0 .022 X_{1}+0.822 X_{2}+4.885 X_{3} \\
& -1.997 X_{4}+0.039 X_{5}+0.089 X_{6}+0.704 X_{7},
\end{aligned}
$$

dengan $R^{2}$ yang diperoleh sebesar $67.8 \%$. Dengan menggunakan model tersebut, dilakukan pendeteksian outlier.

Pada pendeteksian outlier dengan R-student diperoleh bahwa pengamatan ke 7,26, dan 28 merupakan outlier karena memiliki nilai $\left|t_{i}\right|>2.02453$. Hasil perhitungan R-students dapat dilihat pada tabel berikut.

Tabel 1. Pendeteksian Outlier

\begin{tabular}{|c|c|}
\hline Data ke & $\boldsymbol{t}_{\boldsymbol{i}}$ \\
\hline 7 & $\mathbf{- 3 . 4 6 1 8 2}$ \\
\hline 26 & $\mathbf{2 . 2 2 7 8 5}$ \\
\hline 28 & $\mathbf{- 2 . 0 3 4 9 1}$ \\
\hline
\end{tabular}

Selanjutnya akan dideteksi apakah pengamatan ke 7,26 dan 28 merupakan pengamatan berpengaruh yang dapat dilihat pada tabel berikut.

Tabel 2. Pendeteksian Pengamatan Berpengaruh

\begin{tabular}{|c|c|c|c|}
\hline Data ke & $\boldsymbol{D}_{\boldsymbol{i}}$ & $\boldsymbol{D F F I T}_{\boldsymbol{i}}$ & $\boldsymbol{C O \boldsymbol { V } \boldsymbol { R } \boldsymbol { A T I O }} \boldsymbol{i}$ \\
\hline 7 & $0.54861^{*}$ & $-2.65796^{*}$ & $0.03031^{*}$ \\
\hline 26 & $0.53600^{*}$ & $2.22863^{*}$ & 0.57526 \\
\hline 28 & $0.15442^{*}$ & $-1.17702^{*}$ & 0.51894 \\
\hline
\end{tabular}

Tabel 3. Pendeteksian Pengamatan Berpengaruh Lanjutan

\begin{tabular}{|c|c|c|c|c|c|c|c|c|}
\hline Data ke & $D B_{0, i}$ & $D B_{1, i}$ & $D B_{2, i}$ & $D B_{3, i}$ & $D B_{4, i}$ & $D B_{5, i}$ & $D B_{6, i}$ & $D B_{7, i}$ \\
\hline 7 & 0.096 & $-2.056^{*}$ & 0.230 & -0.225 & $-0.345^{*}$ & 0.576 & $0.327^{*}$ & $1.043^{*}$ \\
\hline 26 & $1.485^{*}$ & -0.311 & $-1.063^{*}$ & 0.193 & $-0.933^{*}$ & $1.254^{*}$ & 0.193 & $-1.23^{*}$ \\
\hline 28 & $-0.678^{*}$ & 0.225 & $-0.489^{*}$ & $0.402^{*}$ & $0.794^{*}$ & 0.170 & 0.006 & $-0.451^{*}$ \\
\hline
\end{tabular}

* pengamatan berpengaruh 
Dari Tabel 2 dan Tabel 3 dapat dilihat, pengamatan ke 7, 26 dan 28 merupakan pengamatan berpengaruh paling tidak terhadap tujuh indikator dari empat metode pendeteksian pengamatan berpengaruh.

\subsection{Analisis Faktor-Faktor yang Mempengaruhi Jumlah Kematian Balita}

Dengan menggunakan metode MM-Estimator, diperoleh persamaan regresi:

$$
\begin{aligned}
\widehat{y}= & 4.748348+0.028699 X_{1}+0.831235 X_{2}+5.707692 X_{3} \\
& -1.520916 X_{4}-0.003984 X_{5}-0.035122 X_{6}+0.458624 X_{7} .
\end{aligned}
$$

Selanjutnya, dilakukan uji signifikansi parameter regresi robust untuk semua variabel bebas yang dapat dilihat pada tabel berikut.

Tabel 4. Uji Signifikansi Parameter MM-Estimator

\begin{tabular}{|l|c|}
\hline Variabel & MM- Estimator \\
\hline Jumlah Kasus Pneumonia $\left(X_{1}\right)$ & $7.844^{*}$ \\
\hline Persentase Penanganan Komplikasi Kebidanan $\left(X_{2}\right)$ & 1.523 \\
\hline Persentase Berat Bayi Lahir Rendah $\left(X_{3}\right)$ & 1.059 \\
\hline Persentase Balita Mendapat Vitamin A $\left(X_{4}\right)$ & -0.646 \\
\hline Jumlah Kasus Gizi Buruk $\left(X_{5}\right)$ & -0.045 \\
\hline Persentase Imunisasi BCG $\left(X_{6}\right)$ & -0.135 \\
\hline Persentase Imunisasi Hb $\left(X_{7}\right)$ & 1.176 \\
\hline
\end{tabular}

Variabel bebas dikatakan berpengaruh terhadap variabel tak bebas jika $\left|t_{0}\right|>$ $t_{\alpha / 2, n-(k+1)}$ dengan $n$ adalah banyak data yaitu $38, k$ adalah banyak variabel bebas yaitu 7 , dan $\alpha=0.05$ diperoleh $t_{\alpha / 2, n-(k+1)}=t_{0.025,30}=2.042$. Pada Tabel 4 dapat dilihat variabel bebas $X_{1}$ berpengaruh signifikan terhadap variabel tak bebas.

Dari hasil uji signifikansi, selanjutnya dilakukan estimasi parameter pada variabel bebas yang signifikan, diperoleh model

$$
\widehat{y}=27.119+0.028 X_{1},
$$

dengan $R^{2}$ yang diperoleh sebesar $71.24 \%$.

Berdasarkan model tersebut terlihat bahwa semakin tinggi jumlah kasus pneumonia pada balita $\left(X_{1}\right)$ maka juga semakin tinggi jumlah kematian balita. Pada model dapat dilihat bahwa jika presentase kasus pneumonia pada balita meningkat $1 \%$ maka jumlah kematian akan meningkat sebesar 0.028 .

\section{Kesimpulan}

Berdasarkan hasil penelitian diambil kesimpulan :

(1) Model regresi robust MM-estimator yang menggambarkan faktor yang mempengaruhi jumlah kematian balita di Provinsi Jawa Timur tahun 2017 adalah

$$
Y=27.119+0.028 X_{1} .
$$


(2) Berdasarkan regresi robust MM-estimator, faktor yang mempengaruhi jumlah kematian balita di Jawa Timur pada tahun 2017 adalah pneumonia pada balita.

\section{Ucapan Terima kasih}

Penulis mengucapkan terimakasih kepada Ibu Izzati Rahmi HG M.Si, Ibu Radhiatul Husna M.Si dan Ibu Monika Rianti Helmi M.Si yang telah memberikan masukan dan saran sehingga paper ini dapat diselesaikan dengan baik.

\section{Daftar Pustaka}

[1] Belsley, David A., Kuh, Edwin and Welsch, Roy E. 2004. Regression Diagnostics. New York: John Wiley and Sons.

[2] Chen, C. 2002. Robust Regression and Outlier Detection with the ROBUSTREG Procedure. Paper 265-27. North Carolina: SAS Institute.

[3] Draper, N.R snd Smith, H. 1992. Applied Regression Analysis, Second Edition. John Wiley and Sons, Inc. New York.

[4] Ghozali, I. 2009. Aplikasi Analisis Multivariate dengan Program SPSS. Semarang : UNDIP.

[5] Kementrian Kesehatan RI. 2018. Profil Kesehatan Jawa Timur 2017. Surabaya.

[6] Maronna, R., Douglas Martin and Yohai. 2006. Robust Statistics. John Wiley and Sons. England.

[7] Mashitah, A.W., Indriani D. 2013. Metode Regresi Robust Regression On Ordered Statistics pada Data Tersensor Kiri dengan Outlier. Jurnal Biometrika dan Kependudukan.

[8] Montgomery, D. C., Peck, E. A. 1992. Introduction to Linear Regression Analysis, 2nd edition. John Wiley \& Sons, Inc. New York.

[9] Rousseuw, P. J., dan Leroy, A.M. 1987. Robust Regression and Outlier Detection. John Wiley dan Sons. New York.

[10] World Health Organizations. 2015. Health in 2015 : From MDGs to SDGs. Switzerland. 